\section{Mixed Hemangioma Concur- rence with Giant Concha Bullosa Arising from the Middle Concha}

Sir,

A 71-year woman presented with persistent epistaxis for two years without a history of nasal trauma or surgery. On physical examination, a red-purple mass obstructing the entrance of the right nasal passage was observed. The nasal septum was deviated to the left and a large concha bullosa (CB) was detected on the same side. Contrast-enhanced maxillofacial computed tomography (CT) revealed a $2.5 \mathrm{~cm}$ in diameter, heterogeneous, and irregular soft tissue density mass connected to the middle concha and the anterior septum. A large CB, $3.5 \mathrm{~cm}$ in diameter, originating from the middle concha, was also observed. The CB was adjacent to the soft tissue density mass (Figure 1a). No mass was detected in paranasal sinus CT, which was performed three years ago, due to symptoms possibly associated with sinusitis, except for the CB with the same size. The mass and $C B$ were removed totally and submitted to the pathology laboratory with preliminary diagnoses of hemangioma, pyogenic granuloma, and soft tissue malignancy. Histopathological examination of the mass revealed numerous, thinwalled, erythrocyte-containing cavernous, and capillary vessels in a polypoid mucosa covered by respiratory epithelium (Figure 1b). The epithelium showed localised squamous metaplasia. Focal hyalinisation and foci of dystrophic calcification were also observed. Histopathological examination of CB showed cystic cavities lined with the respiratory epithelium. The cystic cavities were surrounded by an edematous and inflamed fibrous stroma containing seromucous glands and numerous vascular structures. The outer respiratory epithelium also showed localised squamous metaplasia (Figure 1c). Vascular structures were positively stained with CD31 and CD34 in hemangioma (Figure 1d).

In general, hemangiomas are classified as capillary, cavernous, and mixed type according to the predominant type of vessels. ${ }^{1}$ Histologically, the nasal septum is rich in nasal capillary structures, while the concha contains soft tissue rich in venous vessels. It has been reported that capillary hemangiomas of the nasal cavity usually originate from the septum, while the cavernous hemangiomas are often associated with the lateral wall. ${ }^{2}$ The fact that the lesion is related to both the concha and septum may explain the mixed nature of the vascular proliferation observed in the present case.

$\mathrm{CB}$ is a cystic anatomical variation of the middle concha. Mixed type hemangiomas, originating from the middle concha, have been reported in several cases. ${ }^{3}$ To the best of authors' knowledge, however, no case of mixed hemangioma accompanied by a giant $\mathrm{CB}$ related with both the middle concha and anterior septum has been reported so far. It is hypothesised that the compression effect of the giant CB might have caused abnormal vascular proliferation and hemangioma formation.

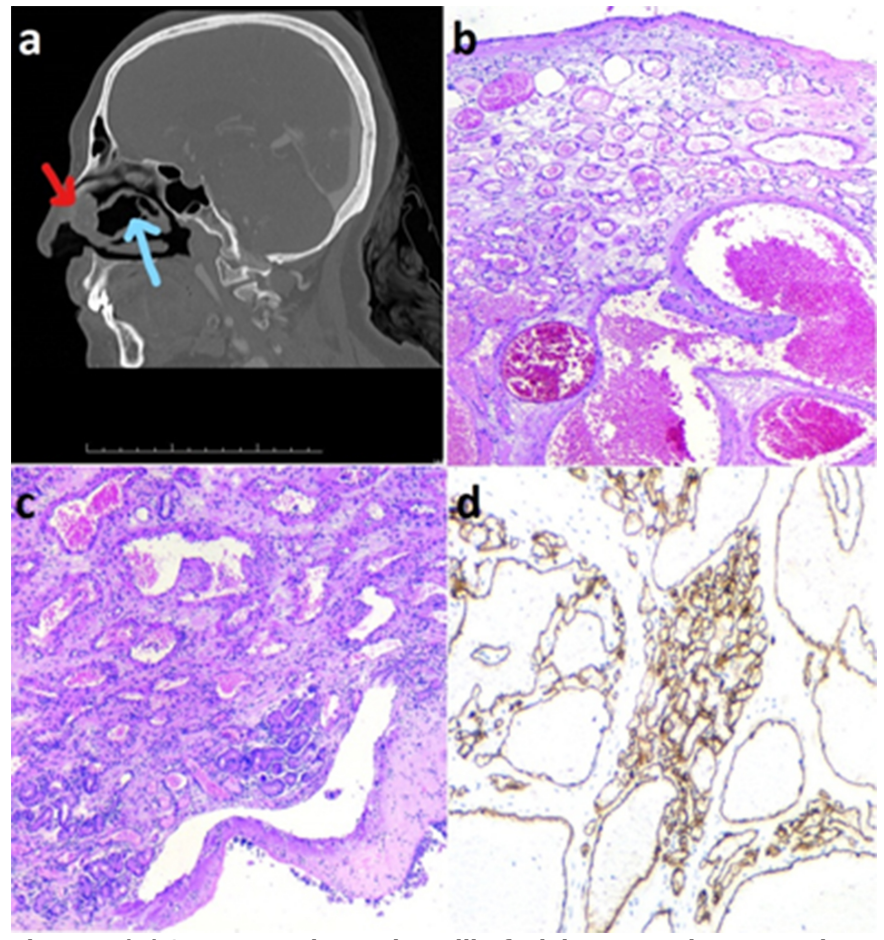

Figure 1: ( a) Contrast-enhanced maxillo-facial computed tomography; a soft tissue density mass connected to the middle concha and the anterior septum (red arrow). Concha bullosa (CB), originating from the middle concha, is also seen. The CB is adjacent to the soft tissue density mass (blue arrow). (b) Mixed type hemangioma; cavernous and capillary vessels in a polypoid mucosa covered by respiratory epithelium (H\&E, $\times 50)$. (c) Concha bullosa (H\&E, $\times 50$ ). (d) Endothelial cells are positively stained with CD34 in hemangioma (CD34, $\times 50)$.

To conclude, in cases of epistaxis, hemangiomas should be taken into consideration and patients with nasal hemangiomas should be evaluated for anatomical abnormalities that may cause pressure with a mass effect. On the other hand, angiofibroma, glomangioma, hemangioendothelioma, lymphangioma, and hemangiopericytoma should be kept in mind in the histological differential diagnosis of hemangiomas.

\section{CONFLICT OF INTEREST:}

The authors declared no conflict of interest.

\section{AUTHORS' CONTRIBUTION:}

AK: Authored the manuscript, and involved in revising it critically for important intellectual content.

HS: Contributed to the analysis and conception.

OFE: Designing and editing manuscript.

\section{REFERENCES}

1. Özkırış M, Aydın R, Seçkin S, Saydam L. A rare cause of pediatric nasal obstruction and epistaxis: Nasal septal mixed hemangioma. Int J Pediatr Otorhinolaryngol Extra 2013; 8(3):104-7. doi.org/10.1016/j.pedex.2013.07.002. 
2. Penezić A, Čupić H, Baudoin T. Mixed type haemangioma of the inferior turbinate: A rare cause of epistaxis. Indian J Otolaryngol Head Neck Surg 2019; 71(3):1695-8. doi: 10.1007/s12070-016-0975-3.

3. Cho EY, Lee JD, Song JW, Kim MG. A mixed hemangioma originated from the middle turbinate. Korean J Otorhinolaryngol-Head Neck Surg 2003; 46(10):882-5.

Asuman Kilitci ${ }^{1}$, Harun Soyalic ${ }^{2}$ and Omer Faruk Elmas ${ }^{3}$

${ }^{1}$ Department of Medical Pathology, Faculty of Medicine, Kirsehir Ahi Evran University, Turkey

${ }^{2}$ Department of Otorhinolaryngology, Faculty of Medicine,
Kirsehir Ahi Evran University, Turkey

${ }^{3}$ Department of Dermatology, Faculty of Medicine, Kirsehir Ahi Evran University, Turkey

Correspondence to: Dr. Asuman Kilitci, Department of Medical Pathology, Faculty of Medicine, Kirsehir Ahi Evran University, Turkey

E-mail:dr.asuk@gmail.com

Received: May 16, 2020; Revised: June 27, 2020;

Accepted: July 02, 2020

DOI: https://doi.org/10.29271/jcpsp.2021.05.615 